\title{
VERIFICATION OF ANAEROBIC THRESHOLD INDICATORS FOR CROSS-COUNTRY SKIERS IN NATURAL CONDITONS
}

\author{
Verification of anaerobic threshold indicators
}

\author{
ANDRZEJ KLUSIEWICZ1 ${ }^{1}$ WIESŁAW CEMPA²
}

\author{
${ }^{1}$ Institute of Sport in Warsaw, Department of Physiology \\ 2 Polish Skiing Association
}

\begin{abstract}
Mailing address: Andrzej Klusiewicz, Institute of Sport, Department of Physiology, 2/16 Trylogii Street, 01-982 Warszawa, tel.: +48 508269190, fax: +48 22 8350977, e-mail: andrzej.klusiewicz@insp.waw.pl
\end{abstract}

\begin{abstract}
Introduction. The objective of this paper was to verify hart rate values for the anaerobic threshold in cross-country skiers during longterm submaximal intensity training effort. Material and methods. Stress tests were conducted for 6 athletes (4 female and 2 male members of the Polish National Team). The first test involved a graded-intensity laboratory stress test on a mechanical treadmill which consisted of 5-minute exercising periods and enable determining the anaerobic threshold values. The subsequent test (performed within 2-7 days after the first test) involved a submaximal intensity run test based on the determined heart rate (HR) ranges for $400 \mathrm{~m}$ on a tartan track. The test involved a 10-minute run done three times at a given intensity based on the HR values for blood lactate level at $4 \mathrm{mmol} / \mathrm{l}$ (HRppa), previously determined during the laboratory tests. First exercise: a run at a speed corresponding to HRppa minus 10 bpm, second exercise: HRppa minus $5 \mathrm{bpm}$ and third exercise: HRppa. Results. The verification of the HRppa values recorded in the laboratory tests on a mechanical treadmill confirmed that this indicator is moderately useful for the purpose of selecting the exercise load during race trainings in natural conditions. Conclusion. The race speeds determined on a mechanical treadmill for the anaerobic threshold need to be corrected (increased speed) for the purpose of finding similar exercise load for race trainings in natural conditions.
\end{abstract}

Key words: cross-country skiers, tests in laboratory and natural conditions, anaerobic threshold, HR range

\section{Introduction}

Anaerobic threshold is generally used for assessment of adaptation to exercising during trainings of cross-country skiers [1, 2]. Also training intensity is planned on the basis of the threshold exercise load. It is generally assumed that the anaerobic threshold is the upper limit of the exercise load which can be realised based on aerobic metabolism [3]. Additionally, trainings for cross-country skiers often take place in various natural conditions (e.g. flat areas, ascents) where ordinarily it is not possible to assess training intensity based on lap time measurements. Thus, heart rate (HR) recorded value is the essential indicator in such circumstances. It should also be noted that so-called HR for the anaerobic threshold is only one precisely determined value, while during trainings HR ranges are used on account of cardiovascular drift, i.e. HR increase as exercises continue [4]. It is worth mentioning that further optimisation of the exercise load to develop endurance is possible based on the concept of the socalled Maximal Lactate Steady State (MLSS) [4, 5]. MLSS refers to the upper blood lactate level during steady exercise when lactate generation and utilisation are in equilibrium [6]. It is emphasised that MLSS plays a vital role in establishing effective training schemes aimed at increasing efficiency and reducing the risk of an injury and overtraining [7]. These issues continue to attract rather strong interest of researchers who have recently been seeking to find a simple method for determining MLSS [7, 8]. A rarely endeavoured attempt to apply HR ranges as determinants of lactate equilibrium is particularly interesting [9]. Similarly, this study was carried out under an assumption that the HR threshold value determined in laboratory conditions is the main upper intensity limit for developing endurance in natural conditions. The objective of this paper was to verify HR values for the anaerobic threshold in cross-country skiers during long-term submaximal intensity training.

\section{Material and methods}

Physical stress tests were performed during the period of general preparation for 6 professional skiers (4 female and 2 male members of the National Team). Profiles of the study subjects are shown in Table 1.

Table 1. Profiles of the female cross-country skiers $(n=4)$ and male cross-country skiers $(n=2)$ included in the study

\begin{tabular}{|c|c|c|c|c|c|}
\hline $\begin{array}{c}\text { Study } \\
\text { subject }\end{array}$ & $\begin{array}{c}\text { Age } \\
\text { (years) }\end{array}$ & $\begin{array}{c}\text { Body height } \\
(\mathrm{cm})\end{array}$ & $\begin{array}{c}\text { Body mass } \\
(\mathrm{kg})\end{array}$ & $\begin{array}{c}\text { Years of } \\
\text { training }\end{array}$ & $\begin{array}{c}\mathrm{VO}_{2} \mathrm{max} \\
(\mathbf{m l} / \mathbf{k g} / \mathbf{m i n})\end{array}$ \\
\hline \multicolumn{7}{|c|}{ Female cross-country skiers } \\
\hline 1. A & 20.4 & 168 & 62.5 & 5 & 51.7 \\
\hline 2. B & 23.3 & 160 & 55.6 & 10 & 57.8 \\
\hline 3. C & 23.8 & 170 & 56.6 & 7 & 60.0 \\
\hline 4. D & 23.9 & 165 & 52.5 & 13 & 53.1 \\
\hline \multicolumn{7}{|c|}{ Male cross-country skiers } \\
\hline 5. E & 28.2 & 177 & 73.0 & 13 & 59.3 \\
\hline 6. F & 35.3 & 177 & 74.0 & 20 & 57.0 \\
\hline
\end{tabular}

The first test to have been performed was a laboratory stress test on a mechanical treadmill consisting of 5-minute periods of physical exercise. The initial treadmill slope was $1.5 \%$ and the initial speed was $10 \mathrm{~km} / \mathrm{h}$ (females) and $12 \mathrm{~km} / \mathrm{h}$ (males). The running speed was increased by $2 \mathrm{~km} / \mathrm{h}$ in the following exercise periods. During the fifth exercise period at a constant speed of $16 \mathrm{~km} / \mathrm{h}$ (females) and $18 \mathrm{~km} / \mathrm{h}$ (males) the initial slope was increased by $1.5 \%$ and then every 2 minutes as long as it was not stopped by the study subject. The above-described test is routinely applied to measure physical fitness of country-cross 
skiers in the National Team. The subsequent test performed within 2-7 days after the laboratory test included a submaximal intensity run test based on the HR ranges for a $400 \mathrm{~m}$ run on a tartan track. The objective of the test was to verify HR ranges during an intense endurance training. The test was preceded by a 5-minute warm-up with HR intensity ranging from 130 to 140 bpm, followed by a 3-minute break. The test involved a 10-minute run done 3 times at a pre-determined intensity based on the HR threshold values (HRppa), earlier determined during the laboratory tests on a mechanical treadmill. The following intensity levels were used: first exercise - run at a speed corresponding to HRppa minus $10 \mathrm{bpm}$, second exercise - HRppa minus $5 \mathrm{bpm}$ and third exercise - at the level of HRppa. The study subjects maintained the pre-determined HR value for submaximal intensity exercise of 2 to 10 minutes. 1.5-minute breaks were organised between the tests to take blood samples.

During the laboratory test gas exchange ratios (lung ventilation, oxygen uptake and carbon dioxide evacuation) were recorded on a continuous breath-by-breath $(\mathrm{BxB})$ basis using SensorMedics Vmax29 (Yorba Linda, CA, USA). The parameters determined on a continuous basis during both tests included heart rate (HR) recorded using Polar recorder (Polar Electro Oy, Finland), and blood lactate level (LA) during the breaks between the tests (in laboratory and natural conditions) and within 4 minutes after the laboratory test using LP400 photometer (Dr Lange, Germany).

The anaerobic threshold (PPA) was interpolated for blood lactate level of $4 \mathrm{mmol} / \mathrm{l}$ [10] based on the laboratory stress test results. The average values of the test parameters and standard deviation (SD) were calculated.

\section{Results}

Table 2 shows the values of the selected indicators at the level of the anaerobic threshold, determined during the test on a mechanical treadmill. The HR threshold was $165-176 \mathrm{bpm}$, i.e. $88-91 \%$ of the maximal HR. Such high HR proportion was characteristic for professional sportsmen practicing endurance disciplines. The obtained $400 \mathrm{~m}$ lap times, HR values and blood lactate levels for the anaerobic threshold and during the submaximal intensity run test on a tartan track ( $3 \times 10 \mathrm{~min})$ for the study subjects are shown in Tables 3 and 4 . It should be noted that only one female skier (C) was determined to have blood lactate level after $30 \mathrm{~min}$ higher than the anaerobic threshold (4.89 $\mathrm{mmol} / \mathrm{l}$ ), while this indicator was similar (E-4.05) or explicitly below the lactate level of $4.0 \mathrm{mmol} / \mathrm{l}$ for the other subjects (Tab. 3). The study subjects were observed to have increased lactate levels during the last $20 \mathrm{~min}$ of the test within the range of $0.2-1.6$ mmol/l, except for the skier A - no changes (Tab. 4). The obtained HR range for exercise of 10-30 min in accordance with the test objectives was similar to $10 \mathrm{bpm}(10-13 \mathrm{bpm})$.

Table 2. Results for the selected exercise indicators recorded in the mechanical treadmill tests in female cross-country skiers $(\mathrm{n}=4)$ and male cross-country skiers $(\mathrm{n}=2)$

\begin{tabular}{|c|c|c|c|c|}
\hline $\begin{array}{c}\text { Study } \\
\text { subject }\end{array}$ & $\begin{array}{c}\text { Speed } \\
(\mathbf{k m} / \mathbf{h})\end{array}$ & $\begin{array}{c}\text { HRppa } \\
(\text { bpm })\end{array}$ & $\begin{array}{c}\text { HRmax } \\
(\text { bpm })\end{array}$ & $\begin{array}{c}\text { HRppa } \\
\text { (\% IRmax })\end{array}$ \\
\hline \multicolumn{6}{|c|}{ Female cross-country skiers } \\
\hline 1. A & 12.2 & 176 & 193 & 91 \\
\hline 2. B & 14.2 & 173 & 194 & 89 \\
\hline 3. C & 14.1 & 172 & 189 & 91 \\
\hline 4. D & 12.8 & 176 & 194 & 91 \\
\hline \multicolumn{6}{|c|}{ Male cross-country skiers } \\
\hline 5. E & 15.0 & 167 & 187 & 89 \\
\hline 6. F & 14.1 & 165 & 187 & 88 \\
\hline
\end{tabular}

Klusiewicz and Cempa: VERIFICATION OF ANAEROBIC...

Table 3. $400 \mathrm{~m}$ lap times, HR values and blood lactate levels (LA) during the run tests (graded-intensity test on a mechanical treadmill and based on the HR range on a tartan track) in female cross-country skiers $(n=4)$ and male cross-country skiers $(n=2)$

\begin{tabular}{|c|c|c|c|c|c|c|}
\hline $\begin{array}{c}\text { Study } \\
\text { subject }\end{array}$ & Indicator & PPA & $10 \mathrm{~min}$ & $20 \mathrm{~min}$ & $30 \mathrm{~min}$ & $\begin{array}{c}\text { Average } \\
\text { LA }\end{array}$ \\
\hline \multicolumn{7}{|c|}{ Female cross-country skiers } \\
\hline \multirow{3}{*}{ 1. A } & $400 \mathrm{~m}$ (min:sec) & $1: 58$ & $1: 50$ & $1: 46$ & $1: 43$ & \\
\hline & HR (bpm) & 176 & 166 & 170 & 178 & \\
\hline & $\mathrm{LA}(\mathrm{mmol} / \mathrm{l})$ & 4.0 & 2.28 & 2.12 & 2.24 & 2.2 \\
\hline \multirow{3}{*}{ 2. B } & $400 \mathrm{~m}$ (min:sec) & $1: 41$ & $1: 45$ & $1: 42$ & $1: 37$ & \\
\hline & HR (bpm) & 173 & 163 & 168 & 176 & \\
\hline & $\mathrm{LA}(\mathrm{mmol} / \mathrm{l})$ & 4.0 & 2.07 & 2.06 & 2.78 & 2.3 \\
\hline \multirow{3}{*}{ 3. $\mathrm{C}$} & $400 \mathrm{~m}$ (min:sec) & $1: 42$ & $1: 43$ & $1: 41$ & $1: 37$ & \\
\hline & HR (bpm) & 172 & 162 & 166 & 172 & \\
\hline & $\mathrm{LA}(\mathrm{mmol} / \mathrm{l})$ & 4.0 & 3.78 & 3.97 & 4.89 & 4.2 \\
\hline \multirow{3}{*}{ 4. D } & $400 \mathrm{~m}$ (min:sec) & $1: 53$ & $1: 46$ & $1: 48$ & $1: 42$ & \\
\hline & HR (bpm) & 176 & 166 & 173 & 177 & \\
\hline & $\mathrm{LA}(\mathrm{mmol} / \mathrm{l})$ & 4.0 & 2.75 & 2.39 & 3.07 & 2.7 \\
\hline \multicolumn{7}{|c|}{ Male cross-country skiers } \\
\hline \multirow{3}{*}{ 5. E } & $400 \mathrm{~m}$ (min:sec) & $1: 36$ & $1: 36$ & $1: 32$ & $1: 28$ & \\
\hline & HR (bpm) & 167 & 157 & 161 & 167 & \\
\hline & $\mathrm{LA}(\mathrm{mmol} / \mathrm{l})$ & 4.0 & 2.43 & 2.68 & 4.05 & 3.1 \\
\hline \multirow{3}{*}{ 6. F } & $400 \mathrm{~m}$ (min:sec) & $1: 42$ & $1: 47$ & $1: 44$ & $1: 40$ & \\
\hline & HR (bpm) & 165 & 155 & 161 & 166 & \\
\hline & $\mathrm{LA}(\mathrm{mmol} / \mathrm{l})$ & 4.0 & 1.93 & 2.13 & 2.17 & 2.1 \\
\hline
\end{tabular}

Key: PPA - $400 \mathrm{~m}$ lap time and HR determined for the anaerobic threshold (lactate level at $4 \mathrm{mmol} / \mathrm{l}$ ) during the test on a mechanical treadmill; 10, 20 and $30 \mathrm{~min}$ - results for the exercise indicators during the tartan track test; Average LA - calculated for the lactate level after 10, 20 and 30 min of exercising

Table 4. Blood lactate level (LA) kinetics and HR ranges during the tartan track run test $(3 \times 10 \mathrm{~min})$ in female cross-country skiers $(n=4)$ and male cross-country skiers $(n=2)$

\begin{tabular}{|c|c|c|c|c|c|}
\hline \multirow{2}{*}{$\begin{array}{l}\text { Test } \\
\text { subject }\end{array}$} & \multirow{2}{*}{$\begin{array}{l}\text { Average } \\
\text { LA* }^{*}\end{array}$} & \multirow{2}{*}{$\begin{array}{l}\text { LA difference } \\
\mathrm{ol} / \mathrm{l})\end{array}$} & \multicolumn{2}{|c|}{$\begin{array}{l}\text { Resulting HR range } \\
\text { (bpm) }\end{array}$} & \multirow{2}{*}{$\begin{array}{c}\text { HR } \\
\text { difference } \\
\text { (bpm) }\end{array}$} \\
\hline & & & $10 \mathrm{~min}$ & $30 \mathrm{~min}$ & \\
\hline \multicolumn{6}{|c|}{ Female cross-country skiers } \\
\hline 1. A & 2.2 & 0.0 & 166 & 178 & 12 \\
\hline 2. B & 2.7 & 0.3 & 166 & 177 & 11 \\
\hline 3. $\mathrm{C}$ & 2.3 & 0.7 & 163 & 176 & 13 \\
\hline 4. D & 4.2 & 1.1 & 162 & 172 & 10 \\
\hline \multicolumn{6}{|c|}{ Male cross-country skiers } \\
\hline 5. E & 2.1 & 0.2 & 155 & 166 & 11 \\
\hline 6. F & 3.1 & 1.6 & 157 & 167 & 10 \\
\hline
\end{tabular}

Key: Average LA - calculated for the lactate level after 10, 20 and $30 \mathrm{~min}$ of exercising; LA, HR difference - differences between the lactate levels and $H R$ values respectively after exercising for 10 and 30 minutes

\section{Discussion}

The above-described tests included a small group of Polish senior cross-country skiers at the highest level of sports skills. The objective of the tests stemmed from the fact that in practical trainings it is usually expected that the exercise load for the anaerobic threshold should correspond to the lactate production and utilisation equilibrium $[3,11]$. However, the earlier tests among representatives of various sports disciplines showed that the application of the exercise load corresponding to the constant blood lactate level of $4.0 \mathrm{mmol} / \mathrm{l}$ (so-called anaerobic threshold) to all competitors can cause unexpected blood lactate levels during trainings aimed at developing aerobic physical fitness $[4,12]$. Furthermore, Keskinen et al. [13] showed how the changes in methods for determining the anaerobic threshold (various duration of the exercise load) affect the resulting threshold HR values.

Because in practical trainings it is often attempted to apply laboratory indicators to choose the exercise load in natural con- 
ditions, it became necessary to develop a stress test which could help verify the HR threshold values (HRppa). A model of a submaximal intensity 30-minute test was proposed to enable the assessment of the lactate level and HR increase kinetics during long-term exercise, and thus the selection of a HR range for endurance trainings.

It should be noted that non-invasive methods for selecting training intensity has for a long time been applied in practical trainings as they reduce financial costs and enable greater mental comfort of competitors $[9,14,15]$. In some disciplines, including cross-country skiing, measurements of mechanical parameters which determine exercise intensity, such as e.g. running speed, are rarely used on account of variable natural conditions. In many cases, when HR is the only available indicator to control exercise intensity at a pre-determined level, it is necessary to use HR ranges and not a constant value as in the case of HR determined for the anaerobic threshold. It should be noted that the 30-minute run test of cross-country skiers performed according to HR ranges based on HRppa values proved effective for selecting pre-determined intensity of endurance trainings. The crosscountry skiers included in the study were observed to have blood lactate level lower than $4.0 \mathrm{mmol} / \mathrm{l}$ after completion of the test, and in only two cases it was slightly higher $-4.89 \mathrm{mmol} / \mathrm{l}$ (C) and $4.05 \mathrm{mmol} / \mathrm{l}$ (E) (Tab. 3). The lactate level kinetics was also characterised by small increments (in the last 2 periods of 10 -minute run tests they ranged from 0.0 to $+1.6 \mathrm{mmol} / \mathrm{l}$ respectively) (cf. Tab. 3 and 4). According to the literature data [6], 30-minute exercise with constant increase in lactate level in the last 20 minutes by $1.0 \mathrm{mmol} / \mathrm{l}$ characterises the maximal lactate steady state (MLSS). As 10-minute runs were done during the tests at variable speed, it was impossible to estimate MLSS. The relatively small lactate level increments obtained in the abovedescribed tests can be interpreted as an equilibrium between the production and utilisation of this metabolite which shows that the exercise concerned is aerobic exercise.

Although Foster et al. [9] showed that the exercise load is more effectively selected based on direct measurements of the blood lactate level compared to HR measurements, nonetheless these simple methods, which do not require collecting blood samples, should also be recognised as highly useful. The results of the conducted tests showed in the case of two study subjects (A and F) that the selection of exercise intensity based on HR threshold values involved excessively low blood lactate levels, i.e. about $2.0 \mathrm{mmol} / \mathrm{l}$ (Tab. 3). In such case the results for 30-minute exercise should be re-verified by increasing the initial HR range by $5 \mathrm{bpm}$. However, it should be noted that relatively low blood lactate levels for MLSS were also recorded during the tests of female canoeists: $2.64 \pm 0.12 \mathrm{mmol} / \mathrm{l}$ [7] and oarswomen: $2.72 \pm 0.54 \mathrm{mmol} / \mathrm{l}[4]$. For example, in other tests conducted for ice skaters during their training on ice rink, it was recorded for $68 \%$ of the study subjects that MLSS was only achieved by controlling the intensity based on HR measurements [9].

Interesting results were also obtained by comparing lactate levels and running speed for a mechanical treadmill and tartan track (Fig. 1). It is also worth noticing that lower lactate levels for tartan track compared to the anaerobic threshold (average level for collected blood samples after exercising for 10, 20 and 30 minutes was $1.9 \mathrm{mmol} / \mathrm{l}$ in the case of females and $2.6 \mathrm{mmol} / \mathrm{l}$ in the case of males) were accompanied by better $400 \mathrm{~m}$ lap times recorded in natural conditions. It should also be noted that in other studies different responses were observed between specific exercises in laboratory conditions and exercises in natural conditions $[16,17]$. The studies conducted for canoeists showed no significant differences between HRppa values recorded when exercising in water and using canoe ergometers [18]. However, when an indicator determined in laboratory conditions is used for training in water, it was also postulated that it should be verified in water.

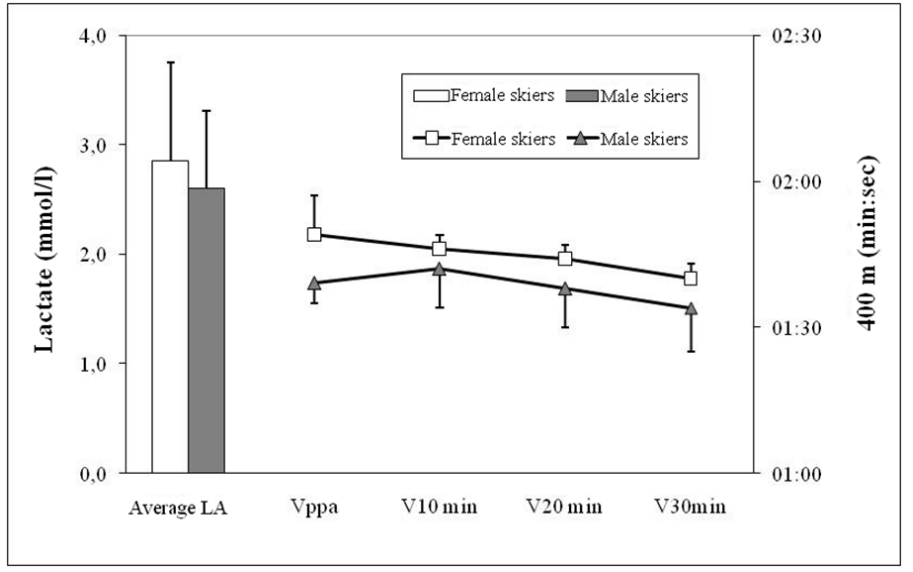

Figure 1. Lactate levels $( \pm S D)$ from three 10 -minute runs on a tartan track and lap times for $400 \mathrm{~m}$ runs (V) determined for the anaerobic threshold on a mechanical treadmill (ppa) and 10minute runs on a tartan track in female skiers $(n=4)$ and senior male skiers $(\mathrm{n}=2)$

\section{Conclusions}

1. The verification of the HR threshold values recorded in the laboratory tests on a mechanical treadmill for the blood lactate level at $4 \mathrm{mmol} / \mathrm{l}$ confirmed that this indicator is moderately useful in selecting the exercise load for race trainings in natural conditions.

2. The race speeds determined on a mechanical treadmill for the anaerobic threshold need to be reviewed and corrected (increased speed) for the purpose of finding similar exercise load for race trainings in natural conditions.

\section{Literature}

1. Klusiewicz, A., Trzaskoma Z., Borkowski L. \& StarczewskaCzapowska J. (2004). An assessment of the specific, exertion-related abilities of first-rate of skiers, runners and biatheletes. Wych. Fiz. Sport 48(3), 207-214. [in Polish]

2. Larsson, P., Olofsson P., Jakobsson E., Burlin L. \& Henriksson-Larsén K. (2002). Physiological predictors of performance in cross-country skiing from treadmill tests in male and female subjects. Scand. J. Med. Sci. Sports 12(6), 347353.

3. Klusiewicz, A. \& Zdanowicz R. (2002). The anaerobic threshold and the state of maximum lactate balance - practical considerations. Sport Wyczyn. 1-2, 58-70. [in Polish]

4. Klusiewicz, A. (2005). Relationship between the anaerobic threshold and the maximal lactate steady state in male and female rowers. Biol. Sport 22, 171-180.

5. Billat, V.L., Sirvent P., Py G., Koralsztein J-P. \& Mercier J. (2003). The concept of maximal lactate steady state. A bridge between biochemistry, physiology and sport science. Sports Med. 33, 407-426.

6. Heck, H., Mader A., Hess G., Mucke S., Muller R. \& Hollmann W. (1985). Justification of the 4-mmol/l lactate threshold. Int. J. Sports Med. 6, 117-130.

7. Diafas, V., Chrysikopoulos K., Diamanti V. \& Kaloupsis S. (2009). Assessment of maximal lactate steady state in elite female kayakers. Med. Sport 13, 43-48. 
8. Laplaud, D., Guinot M. \& Favre-Juvin A. (2006). Maximal lactate steady state determination with a single incremental test exercise. Eur. J. Appl. Physiol. 96, 446-452.

9. Foster, C., Crowe M.P., Holum D., Sandvig S., Schrager M., Snyder A.C. et al. (1995). The bloodless lactate profile. Med. Sci. Sports Exerc. 27, 927-933.

10. Mader, A., Liesen H., Heck H., Philippi H., Schürch P.M. \& Hollmann W. (1976). Assessment of specific sports efficiency in laboratory. Sportartz Sportmed. 27, 80-88. [in German]

11. Beneke, R. (1995). Anaerobic threshold, individual anaerobic threshold, and maximal lactate steady state in rowing. Med. Sci. Sports Exerc. 27, 863-867.

12. Beneke, R. \& Petelin von Duvillard S. (1996). Determination of maximal lactate steady state response in selected sports events. Med. Sci. Sports Exerc. 28, 241-246.

13. Keskinen, K.L., Komi P.V. \& Rusko H. (1989). A comparative study of blood lactate tests in swimming. Int. J. Sports Med. 10, 197-201.
14. Gilman, M.B. \& Wells C.L. (1993). The use of heart rates to monitor exercise intensity in relation to metabolic variables. Int. J. Sports Med. 14, 339-344.

15. Swensen, T.C., Harnish C.R., Beitman L. \& Keller B.A. (1999), Noninvasive estimation of the maximal lactate steady state in trained cyclists. Med. Sci. Sports Exerc. 31, 742-746.

16. Klusiewicz, A., Sitkowski D., Bieńko A., Furdal S. \& Skwarczyński T. (1991). Optimizing the selection of indices for assessing the work capacity of rowers. Biol. Sport 8, 167-175.

17. Urhausen, A., Weiler B. \& Kindermann W. (1993). Heart rate, blood lactate, and catecholamines during ergometer and on water rowing. Int. J. Sports Med. 14, Suppl. 1, S20-23.

18. Sitkowski, D. (2008). The anaerobic threshold of canadian canoers during specific exertions on the water and on a kayak ergometer. Pol. J. Sport Tourism 15, 166-173.

Submitted: April 21, 2011

Accepted: July 6, 2011 